\title{
PREVALENCE OF GASTROINTESTINAL HELMINTHES IN BUFFALOES IN BARISAL DISTRICT OF BANGLADESH
}

\author{
S. S. Saha*, D. R. Bhowmik ${ }^{1}$ and M. M. R. Chowdhury ${ }^{2}$ \\ Department of Pathology and Parasitology, Patuakhali Science and Technology University, Babugonj, Barisal, \\ Bangladesh \\ ${ }^{1}$ MS in Pharmacology, Bangladesh Agricultural University, Mymensingh, Bangladesh \\ ${ }^{2}$ Department of Physiology, Biochemistry and Pharmacology, Patuakhali Science and Technology University, \\ Babugonj, Barisal, Bangladesh
}

\begin{abstract}
A total 270 samples were collected from July 2012 to December 2012 from three upazilas (Barisal sadar, Bakergonj and Mehendigonj) of Barisal district to know the prevalence of gastrointestinal helminthes. Samples were collected in $10 \%$ neutral buffered formalin and shifted to Parasitology laboratory of the department of Pathology and Parasitology under the Animal Science and Veterinary Medicine (ANSVM) faculty of Patuakahli Science and Technology University. Samples were examined by direct smear method and simple sedimentation method of fecal sample examination technique. Among 270 samples 107 (39.6\%) samples were found positive for gastrointestinal helminthes. Five types of helminthes were identified namely Fasciola gigantica (26.17\%), Amphistomes (60.75\%), Neoascaris vitulorum (1\%), Schistosoma bovis (1\%), Trichostrongylus axei (2\%). The prevalence of mixed infection with Fasciola gigantica and Amphistomes was $9.34 \%$. No cestode was found in this study. Comparative study among three different upazila shows highest prevalence in Barisal sadar (44\%) and lowest in Mehendigonj (25\%). Geographical location of different char island of Sadar upazila and season of sample collection may be the cause of highest prevalence of gastrointestinal helminthes in Sadar upazila of the district. Study period covered rainy season and part of winter season only. Highest parasitic ova were found in rainy season (44.32\%) than winter season $(29.41 \%)$. The age specific prevalence were $12.15 \%, 14.02 \%, 40.19 \%, 33.65 \%$ in $0-6$ months, 7 months- 2 years, 3 years- 6 years \& 7 years - above respectively. History of administering anthelmintic (Levamisole hydrochloride) to the calf may be the cause of lowest prevalence of parasitic infection at early age in the study area. In this study, highest number $(60.75 \%)$ of Amphistomes was found among positive cases. Some important Amphistomes of buffalo are Paramphistomum, Cotylophoron, Gigantocotyle, Gastrothylax etc. are difficult to differentiate through fecal sample examination. So, to understand the detail epidemiology, at least a year study using gross morphological examination with molecular characterization of helminthes is needed.
\end{abstract}

Key words: Prevalence, gastrointestinal helminthes, Barisal

\section{INTRODUCTION}

Buffalo is one of the potential animals that can boost meat production in Bangladesh. Total buffalo population in Bangladesh in 2007-08 is 1.3 million. Buffaloes are not only the main source of animal proteins but also their products such as bones, skins and goods made from them are of great economic importance. Buffalo meat is the healthiest meat among red meats known for human consumption since it is low in calories and cholesterol. Buffalo meat and milk are well comparable to cattle in many of the physicochemical, nutritional, functional properties and palatability attributes. Buffaloes are usually raised in extensive system in the coastal areas where large scale pasture land is available. There is no definite ideal management system of buffalo in coastal areas i.e. about housing, breeding, de-worming, vaccination, animal identification and record-keeping. Factors like diseases, genetic makeup, poor nutritional and management practices, environmental stress etc. are major constraints of livestock responsible for the low productivity of buffalo. Among all parasitic infections, mainly those caused by gastrointestinal helminthes are the major problems of our livestock and causes great economic loss to dairy industry by way of retarded growth, low productivity and increased susceptibility of animals to other infections. Economic losses are caused by gastrointestinal parasitism are in a variety of ways: they cause losses through lowered fertility, reduced work capacity, involuntary culling, a reduction in food intake and lower weight gains, lower milk production, treatment costs and mortality in heavily parasitized animals (Lebbie et al., 1994). Chowdhury and Tada (1994) described the prevalence and other factors associated with helminthes of domestic animals in Indian subcontinent causing parasitic gastroenteritis. Watery diarrhea, weakness, weight loss, decreased milk production, reduced product quality, mortality and other secondary infections are caused by trematode parasites (Soulsby, 1982).

\footnotetext{
*Corresponding e-mail address: shib.vet@gmail.com 


\section{S. S. Saha and others}

Helminth parasites are potential health hazard to livestock population and produce enormous economic losses. Fascioliasis is distributed throughout the world (Blood et al., 1990). A coprological survey of gastrointestinal parasites was done by Mamun et al. (2011) in buffalo in Kurigram district of Bangladesh and found 61.02\% positive cases. He detected nine species namely, Paramphistomum cervi (29.24\%), Fasciola gigantica (22.46\%), Schistosoma indicum (1.27\%), Schistosoma spindale (0.85\%), Toxocara vitulorum (2.54\%), Strongyles (0.85\%), Strongyloides sp. (0.42\%), Eimeria sp. (3.39\%) and Balantidium coli (37.29\%). A pathological investigation of liver of the slaughtered buffaloes in Barisal district was conducted by Ahmedullah et al. (2007) and 31.25\%, $22.5 \%$ and $2.5 \%$ cases were infected with Gigantocotyle explanatum (amphistomiasis), Fasciola gigantica and hydatidosis respectively. Due to scarcity of pasture land, buffaloes are usually reared at very remote area of the district having limited access to research. This study describes the prevalence of gastrointestinal helminthes through fecal sample examination technique in buffalo in Barisal district of Bangladesh.

\section{MATERIALS AND METHODS \\ Study area}

Barisal district (Latitude: 22.75, Longitude: 90.36, Altitude: 4.) is located in south-central part of Bangladesh. The maximum annual average temperature is $35.1^{\circ} \mathrm{C}$, minimum $12.1^{\circ} \mathrm{C}$. The annual rainfall is $1955 \mathrm{~mm}$, whereas, maximum rainfall is observed in Rainy season (July to October). A lot of rivers are passing away through Barisal district making different island. Natural pasture land makes the island suitable buffalo rearing area. Barisal District is divided into 10 different upazilas but buffalo is not reared at large scale in all upazilas. Depending on the availability of pasture land, buffalo is usually found at Barisal sadar, Bakergonj and Mehendigonj upazila. In Sadar upazila samples were collected from four places namely; Charpar-North, Charpar-South, Laharhat-I, Laharhat-II (nearer to Mehendigonj upazila).

\section{Collection and examination of fecal samples}

Two hundred and seventy (270) fecal samples were collected randomly from July 2012 to December 2012. Among 270 fecal samples, 185 samples were collected from Barisal sadar upazila, 45 samples from Bakergonj upazila and 40 samples from Mehendigonj upazila. Based on age the buffaloes were categorized into following groups: 0-6 months, $>6$ months-2 years, $>2$ years-6years and $>6$ years- above. Age of the animals were determined by dentition and sometimes by asking buffalo owners. Samples were collected directly from rectum or immediately after defecation using plastic gloves. Physical examination of fecal samples and clinical signs of animals were recorded during feces collection. Collected fecal samples were preserved in neutral buffered formalin in a plastic jar. Samples were sent to the Parasitology laboratory of the department of Pathology and Parasitology under Animal Science and Veterinary Medicine faculty (ANSVM) of Patuakhali Science and Technology University (PSTU) for the identification of various ova and parasite. Fecal samples were screened by direct smear method and simple sedimentation method. The ova of parasites were identified from their morphological features (Soulsby, 1982).

\section{RESULTS AND DISCUSSION}

During this study July 2012 to December 2012 a total of 270 fecal samples were examined through fecal sample examination technique, of which 107 (39.6\%) samples found positive for gastrointestinal helminthes. Five types of parasitic ova were detected namely Fasciola gigantica (26.17\%), Amphistomes (60.75\%), Neoascaris vitulorum (1\%), Schistosoma bovis (1\%), Trichostrongylus axei (1\%). 9.34\% (Fasciola gigantica + Ampistomes) (Figure 1). No cestode was found. Grossly, no adult worm was found in the feces of buffalo. The consistency of the feces varied from firm to liquid. No significant clinical signs were observed in these animals.

Similar results were reported by Jagannath et al. (1988) found 42.12\% incidence of gastrointestinal helminths in buffalo in Karnataka of India. Kashyap et al. (1997) also reported 40.03\% prevalence of gastrointestinal helminthosis in buffalos in Madhay Pradesh with prominent infection of Strongyle and Haemonchus sp. but in this report very few nematodes were found. However, more than 50\% incidence of parasitic infections in cattle and buffaloes has also been recorded from gastrointestinal helminthosis Gujrat (Pethkar and Hiregaudar, 1972), Haryana (Chhabra et al., 1978) and Rajasthan (Godara and Manohar 2004). On the otherhand, Mamun et al. (2011) reported 61.02\% incidence of gastro intestinal helminth in Kurigram district of Bangladesh and Azam et al. (2002) found $64.41 \%$ incidence of internal parasite in buffalo in Pakistan. Cockrill (1974) stated that the buffalo is exposed to a higher risk of infection with snail borne helminthes due to its wallowing behavior. 
More than 70 species of Amphistomes are detected in ruminants in the world. Most pathogenic species cause intestinal amphistomiasis. Adult amphisomes like Explanatum sp. have been found in the bile duct causing severe damage leading to fibrosis in the bile duct and liver (Sing et al. 1958). In liver, Explanatum sp. is attached by their acetabulum and produces granulomatous nodules that are infiltrated by numerous inflammatory cells (Ahmedullah et al., 2007 and Haque et al., 2011). Haque et al. (2011) also reported co-infection i.e., both Fasciola gigantica and Explanatum sp. in one liver that supports this report. In such cases E. explanatum were found to be restricted to main bile ducts whilst $F$. gigantica were localized deep in the intra hepatic ductules.

In this study, highest number of Amphistomes (60.75\%) was found by fecal examination. But through fecal sample examination it is impossible to identify the parasite species using morphological analysis of ova alone. Morphological identification of adult parasite collecting from slaughtered animal may the one option of species identification (Sey, 1991). But it requires specialized knowledge and techniques. The second internal transcribed spacer (ITS2) of ribosomal DNA has been shown to be a useful genetic marker for species identification of amphistomes (Lotfy et al., 2010). In addition, PCR amplification of DNA from individual eggs obtained from three Amphistome species also useful in species identification (Itagaki et al., 2003). Initially morphological characterization of amphistomes followed by molecular characterization is also possible (Ichikawa et al., 2013)

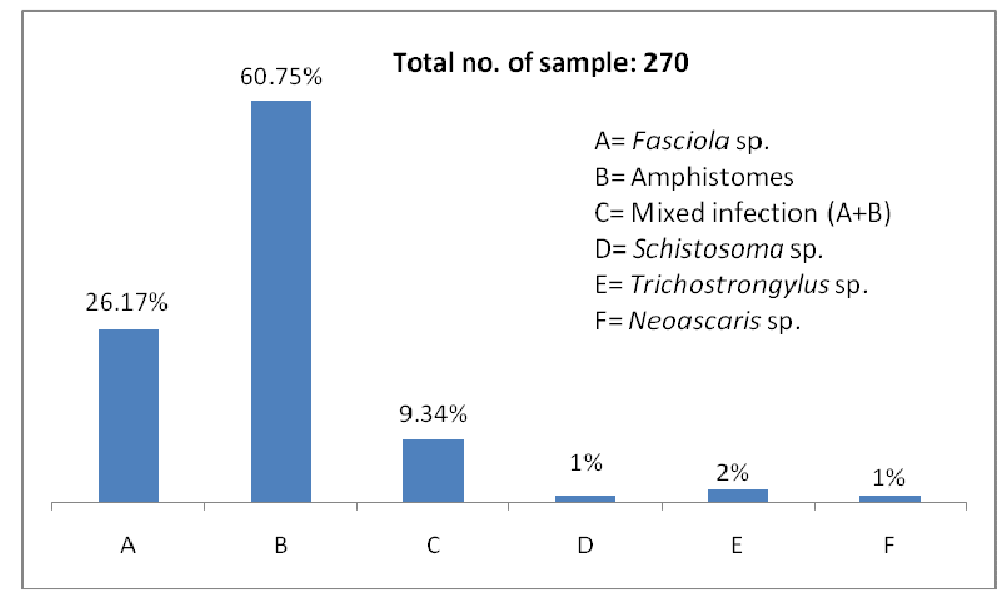

Figure 1. Prevalence of gastro intestinal helminthes in Barisal district

\section{Comparative study of parasitic infection among different upazila}

The study was conducted in three different upazilas of Barisal district namely, Barisal sadar, Bakergonj and Mehendigonj. Among different upazila highest prevalence was found in Barisal sadar (44\%) and lowest in Mehendigonj (25\%) (Figure 2). Season of sample collection with geographical distribution of the buffalo may be the cause highest prevalence of gastrointestinal helminth in buffalo in Sadar upazila.

Samples collected from different char island of Sadar upazila at rainy season (July-October) showed 44.32\% gastro intestinal helminthes (82 positive cases out of 185) positive cases whereas, sample collected during winter from Mehendigonj (samples were collected in November) and Bakergonj upazila (samples were collected in December) showed lowest prevalence $33.33 \%$ (15 positive cases out of 45 ) and 25\% (10 positive cases out of 40 ) respectively. This report is comparable with Mamun et al. (2011) who got highest prevalence in rainy season $(71.17 \%)$ and lowest in winter season (57.27\%) in Kurigram district of Bangladesh. Though the seasonal prevalence rate is higher than our report but overall infection rate in buffalo of Kurigram district $(61.02 \%)$ was higher than Barisal district (39.6\%).

\section{Age related prevalence}

From age related distribution, highest prevalence was found in 3years to 6 years of age $(40.19 \%)$, lowest prevalence was found in $0-6$ months of age (12.15\%) and second most prevalence was found among buffaloes which are 7 years and above age (33.65\%) (Figure 3$)$. 


\section{S. S. Saha and others}

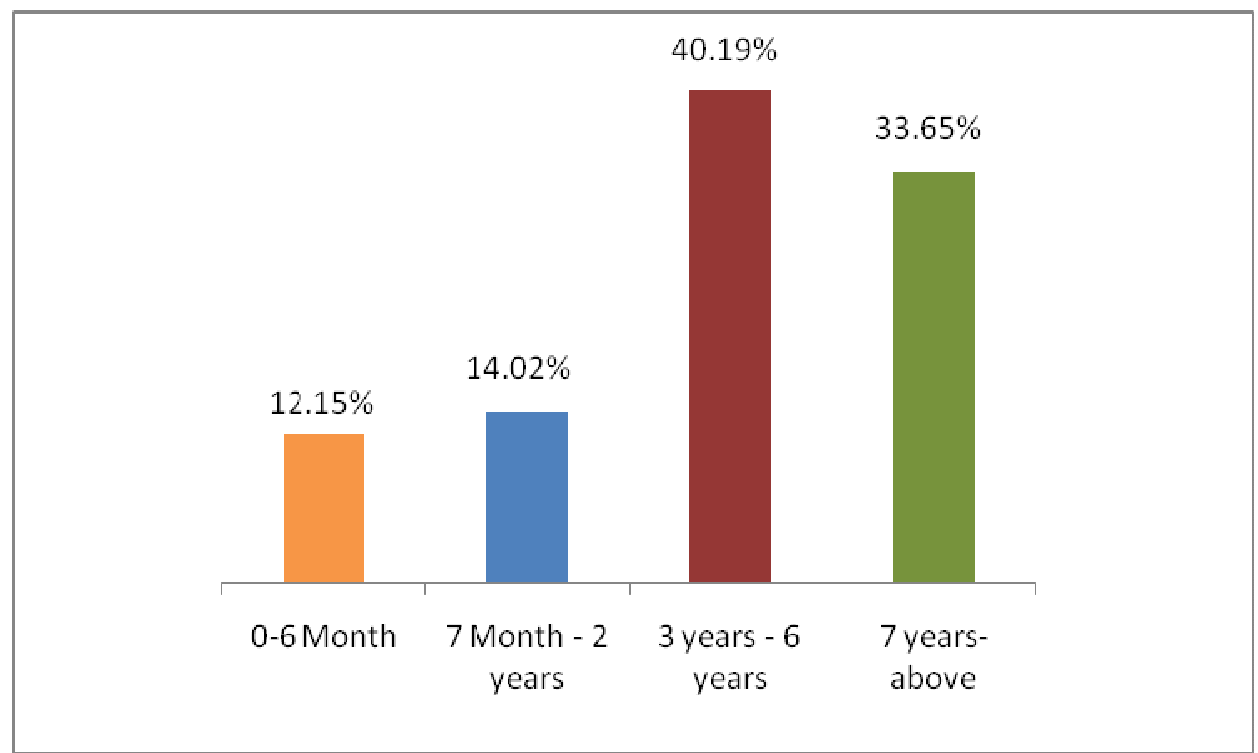

Figure 2. Age related prevalence of parasitic infection in buffalo in Barisal district

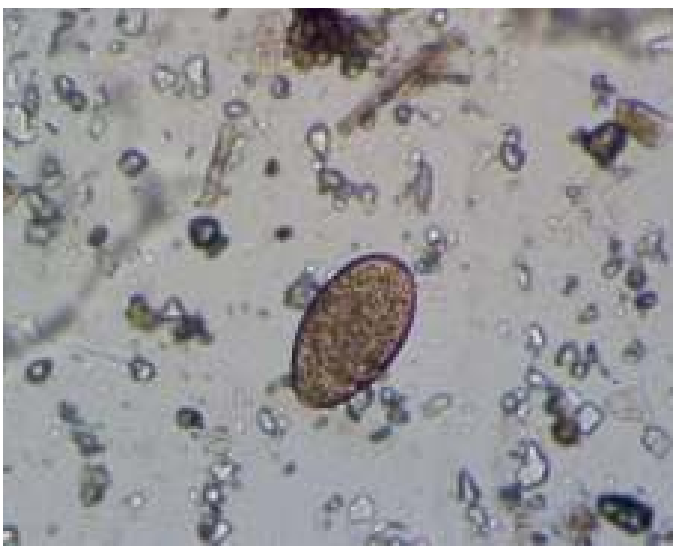

Figure 3. Ova of Fasciola sp.

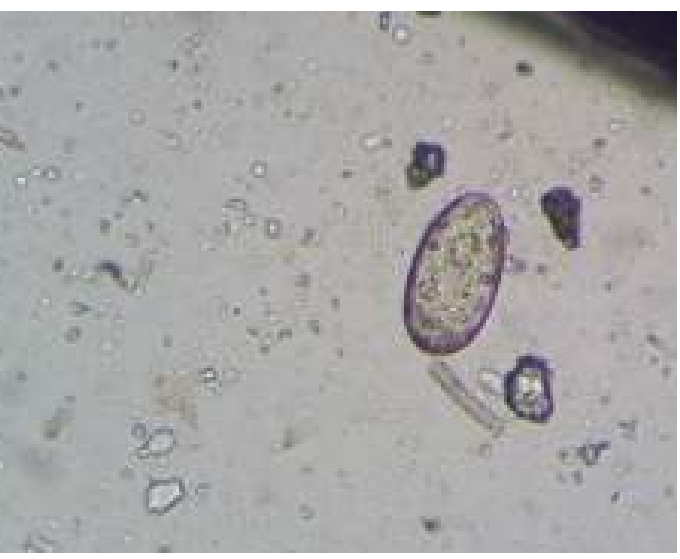

Figure 4. Ova of Paramphistomum sp.

Similarly, Mamun et al. (2011) reported highest prevalence of endoparasite in young buffaloes ( $>2-5$ years) than adult in Kurigram district of Bangladesh and Asif et al. (2007) also reported the higher prevalence of helminth in young than adult in Pakistan. The awareness program on calf mortality due to ascariasis was done through deworming campaign by veterinarian and paravet staff in the study area may be the cause of lower prevalence at young ages.

In conclusion, Amphistomes were more prevalent in buffalo in Barisal district. Usually this group of parasite is neglected during treatment and control strategy but important genera of this group like Paramphistomum, Cotylophoron, Gigantocotyle, Gastrothylax etc. causes substantial economic losses of buffalo production. Fecal examination technique can not differentiate the parasitic ova. So, accurate diagnosis is very important for proper control strategy. Due to limitation of fund the study was conducted in two seasons. Highest positive cases were found in rainy season than winter season. To make an effective control plan against gastrointestinal helminth a year round epidemiological study covering all the buffalo rearing island of South Bengal with proper diagnosis is warranted. 


\section{ACKNOWLEDGEMENT}

We are grateful to Post Graduate Studies Faculty of PSTU for funding the work. We also explicit gratefulness and cordial thanks to the undergraduate students of ANSVM faculty, field staff of DLS, buffalo owners for sample collection from such a remote area and co-operation in every steps of the research.

\section{REFERENCES:}

1. Ahmedullah F, Akbor M, Haider MG, Hossain MM, Khan MAHNA, Hossain MI and Shanta IS (2007). Pathological investigation of liver of the slaughtered buffaloes in Barisal district. Bangladesh Journal of Veterinary Medicine 5 (1 \& 2): 81-85.

2. Asif RM, Iqbal Z, Jabbar A and Yaseen M (2007). Point prevalence of gastrointestinal helminthiasis in ruminant in southern Punjab, Pakistan. Journal of Helminthology 81 (3): 323-328.

3. Azam M, Siddiqui MM and Habib G (2002). Prevalence of parasitic infection in buffalo calves in Khadagzai district. Dir. Pakistan Veterinary Journal 22(2) : 87-90.

4. Blood DC, Radotits OM, Arundle TM and Gay CC (1990). Textbook of Veterinary Medicine. $7^{\text {th }}$ Ed. Bailliere Tindal, London, UK.

5. Chhabra MB, Sharma ML, Tikaram SM and Chawla SK (1978). An outbreak of bovine trypanosomiasis and gastrointestinal parasitism in a flood affected district of Haryana. The Haryana Veterinarian 17(2): 116-120.

6. Chowdhury $\mathrm{N}$ and Tada I (1994). Helminths of domesticated animals in Indian subcontinent, In: Helminthology. Springer-Verlag, Narosa Publishing House, pp. 73-120.

7. Cockrill WR (1974). The working buffalo. In: The Husbandry and Health of the Domestic Buffalo, edited by W.R. Cockrill. Food and Agricultural Organization of the United Nations, Rome, Italy.

8. Godara R and Manohar GS (2004). Prevalence of Gastrointestinal parasitism in different breeds of cattle of Rajasthan. Indian Veterinary Medical Journal $28: 74$

9. Haque M, Mohan C and Ahmad I (2011). Natural trematode infection in liver of water buffalo (Bubalus bubalis): histopathological investigation. Journal of Parasitic Diseases 35(1) : 50-53.

10. Ichikawa M, Kondoh D, Bawn S, Maw NN, Htun LL, Thein M, Gyi A, Sunn K, katakura K and Itagaki T (2013). Morphological and Molecular Characterization of Explanatum Explanatum from Cattle and Buffaloes in Myanmar. The Journal of Veterinary Medical Science 75(3) : 309-314.

11. Itagaki T, Tsumagari N, Tsutsumi K and Chinone S (2003). Discrimination of three amphistome species by PCR-RFLP based on rDNA ITS2 markers The Journal of Veterinary Medical Science 65 : 931-933.

12. Jagannath MS, D'souza PE and Abdul Rahman S (1988). Gastrointestinal parasites of cattle and buffaloes in Bangalore and Mysore Milk Unions. Mysore, Journal of Agricultural Science 22 : 91-96.

13. Kashyap Z, Sisodia RS and Shukla PC (1997). Incidence of gastrointestinal parasites in cattle and buffaloes in Malwa region of Madhya Pradesh. Haryana Veterinarian 36 : 34-36.

14. Lebbie SHB, Rey B and Irungu EK (1994). Small ruminant research and development in Africa, Proceedings of the Second Biennial Conference of the African Small Ruminant Research Network, ILCA (1994), pp. 1-5.

15. Lotfy WM, Brant SV, Ashmawy KI, Devkota RM, Koji GM and Loker ES (2010). A molecular approach for identificationof paramphistomes from Africa and Asia. Veterinary Parasitology 174 : 234-240.

16. Mamun MAA, Begum N and Mondal MMH (2011). A coprological survey of gastrointestinal parasites of water buffaloes (Bubalus bubalis) in Kurigram district of Bangladesh. Journal of the Bangladesh Agricultural University 9(1) : 103-109, 2011.

17. Pethkar DK and Hiregoudar LS (1972). Helminthic infections of cattle and buffaloes in Gujarat state. Gujarat Veterinarian (6) : 30-31.

18. Sey O (1991). CRC Handbook of the Zoology of Amphistomes, 1st ed., CRC Press, Florida.

19. Singh KS (1958). A redescription and life-history of Gigantocotyle explanatum (Creplin, 1847) Nasmark, 1937 (Trematoda; Paramphistomidae) from India. Journal of Parasitology. 44 : 210-224.

20. Soulsby EJL (1982). Helminths, arthropods and protozoa of domesticated animals. 6th Ed. CLBS and Bailliere Tindal. pp. 788. 